THURSDAY, NOVEMBER 27, 1890.

\section{THE UNITED STATES CENSUS.}

$\mathrm{W}^{\mathrm{B}}$ $\mathrm{E}$ are surprised that so little attention is being given here to the totals of the United States census which are just being published. There is no more important record in the life of a people than its census. Accounts of progress are impossible, without it. In the United States, also, special attention is given to the census, partly because it is a requirement of the Constitution, which assigns representatives to States and districts in accordance with the population figures. Every ten years, in the United States, there is a vast outlay on the business, with which outlay nothing spent in Europe can compare. But now there are loud complaints all over the United States that the record for 1890 is zerong; that the population of cities and places has been miscounted grossly. If these complaints are true, the United States might almost as well have had no census at all. All the elaborate work which is to be based on these population figures is rendered useless before it is begun. Apart from the direct loss to the United States people themselves, who lose the information about their own affairs the census might have given them, the whole world sustains a loss in being deprived of comparisons of many kinds with so remarkable a progress as that of the United States. Has a colossal blunder, then, been made? and what can be the reason of it?

That there is a huge blunder, or worse, somewhere, appears quite unmistakable. Those who are interested have only to cast their eye over the following table to see that something unusual happened to the I87o census, and has again happened to the 1890 census :-

Population of the United States, since $\mathrm{I} 800$, and increase in each decennial period.

\begin{tabular}{rrccccc} 
& \multicolumn{3}{c}{$\begin{array}{c}\text { Population } \\
\text { (in thousands). }\end{array}$} & \multicolumn{2}{c}{ Increase. } \\
$\mathbf{1 8 0 0}$ & $\ldots$ & 5,308 & $\ldots$ & Amount. & $\ldots$ & Ptr cent. \\
10 & $\ldots$ & 7,239 & $\ldots$ & 1,931 & $\ldots$ & 36 \\
20 & $\ldots$ & 9,634 & $\ldots$ & 2,395 & $\ldots$ & 33 \\
30 & $\ldots$ & 12,866 & $\ldots$ & 3,232 & $\ldots$ & $33^{\frac{1}{2}}$ \\
40 & $\ldots$ & 17,069 & $\ldots$ & 4,203 & $\ldots$ & 33 \\
50 & $\ldots$ & 23,191 & $\ldots$ & 6,122 & $\ldots$ & 36 \\
60 & $\ldots$ & 31,443 & $\ldots$ & 8,252 & $\ldots$ & $35 \frac{1}{3}$ \\
70 & $\ldots$ & 38,558 & $\ldots$ & 7,115 & $\ldots$ & 23 \\
80 & $\ldots$ & 50,156 & $\ldots$ & 11,598 & $\ldots$ & 30 \\
90 & $\ldots$ & 62,481 & $\ldots$ & 12,325 & $\ldots$ & $24 \frac{1}{3}$
\end{tabular}

In all this long period the increase of population in the United States has been at the nearly uniform rate of a third every ten years, with the two exceptions of the 1870 census and the 1890 census, in which the increase is respectively 23 and $24 \frac{1}{2}$ per cent. only. What can have happened, first between the 1860 census and that of 1870 , and next between the census of 1880 and that of 1890 , to make the results so different from those of all the other periods?

Now, what happened between I 860 and I 870 is partially explainable. These were the years of the great Civil War, in which privation and disease, with death and injuries on the battle-field, had their thousands and millions of victims. Such causes are well known to check the growth of population. Unfortunately, also, there is another partial explanation. It has been admitted on the highest authority, that of General Walker, who supervised the census of 1880 - and the admission is now repeated by the superintendent of the 1890 census-that the figures of the 1870 census were in some States falsified, with the result that in 1880 , when the census of that year was taken, an impossible increase of population appeared to have occurred in those States. As far as amount is concerned, however, the former explanation has always been understood to be the more serious.

Can any such explanation be given of the small increase between 1880 and 1890 ? The answer is obvious. There has been no war or the like occurrence since I 880 to check the growth of population. There is absolutely nothing to suggest why the United States population, having increased most rapidly from the beginning of the century down to 1880 , excepting during the war decade of I 860-70, should have suddenly had its rate of growth arrested.

More than this, the period between I 880 and 1890 has been one in which, according to past experience, owing to the special magnitude of the immigration, the rate of growth should have been as great as in any of the previous periods. The amount, and proportion to the population at the previous census, of the immigration into the United States since I 820 , has been :--

\begin{tabular}{|c|c|c|c|c|c|}
\hline \multirow{3}{*}{$\begin{array}{l}\text { Census period. } \\
\qquad \begin{array}{l}1820-30 \\
1830-40\end{array}\end{array}$} & \multicolumn{3}{|c|}{ Amount. } & \multicolumn{2}{|c|}{$\begin{array}{l}\text { Proportion to } \\
\text { population at the } \\
\text { previous census. }\end{array}$} \\
\hline & $\cdots$ & I 28,000 & $\ldots$ & I'3 & \\
\hline & $\ldots$ & 538,000 & $\ldots$ & $4 \cdot 2$ & , \\
\hline $1840-50$ & $\ldots$ & $\mathrm{I}, 427,000$ & $\ldots$ & $8 \cdot 4$ & , \\
\hline $1850-60$ & $\ldots$ & $2,814,000$ & $\ldots$ & $12 \cdot 2$ & , \\
\hline $1860-70$ & $\ldots$ & $2,264,000$ & $\ldots$ & $7 \cdot 2$ &, \\
\hline $1870-80$ & $\ldots$ & $2,707,000$ & . . & $7^{\circ} \mathrm{O}$ & , \\
\hline $1880-90$ & $\ldots$ & $5,275,000$ & $\ldots$ & 10.5 & , \\
\hline
\end{tabular}

Thus, between I 880 and I 890 , as far as the element of immigration is concerned, the growth of population in the Unites States was as much stimulated as in any previous decade, with the single exception of the $1850-60$ period. There was absolutely no reason, then, why the rate of growth should fall off between 1880 and 1890 , but a special reason why it should not fall off.

When we compare the figures in amount, we are still more bewildered. Between 1870 and I880, with an immigration of $2,707,000$ only, the increase of population is II, 598,000 ; so that, deducting the immigration, the increase which is due to the excess of births over deaths appears to be $8,891,000$. Between 1880 and 1890 , with an immigration of $5,275,000$, the total increase of population is $12,225,000$, and if we deduct the immigration, the increase which is due to the excess of births over deaths appears to be $6,950,000$ only! The excess of births over deaths which was nearly $9,000,000$ between I 870 and I 880 falls to less than 7,000,000 in the following decade, although the population at starting was 25 per cent. greater in the later than in the earlier decade. Making any reasonable correction for the under estimate in the 1870 census itself, which is now admitted, we still find these figures most startling. Even if we were to increase the population of 1870 to $40,000,000$, as the superintendent of the i 890 census now suggests, thus reducing the apparent increase between 1870 and 1880 from about 9,000,000 to about 7,500,000, we should still be confronted by the fact that, starting from a larger population, and with a larger immigration, the excess of

$$
\text { NO. I IOO, VOL. 43] }
$$


births over deaths in $1880-90$ would have been from 25 to 30 per cent. more than in the previous decade, or at least 9,500,000, whereas it appears to be under $7,000,000$. The figures of the $\mathrm{x} 890$ census are, therefore, quite incredible.

The superintendent of the 1890 census has issued an explanation, which does not, we fear, amount to very much. He makes a great deal of the errors in the 1870 census, which we have already glanced at, and asserts that the rate of growth of population, when proper corrections are made, was much less than 30 per cent. in the $1870-80$ period, so that the rate of $24 \frac{1}{2}$ per cent. between I 880 and 1890 does not show a great falling off. But while he makes too much of the 1870 errors in amount, he makes no mention at all of the much larger immigration between $\mathbf{I} 880$ and $\mathbf{I} 890$ than in the previous decade, which should have made a difference of at least $3^{\frac{1}{2}}$ per cent. in the rate of growth in favour of the latter as compared with the former period.

A farther explanation is that there is a permanent tendency for the rate of growth of the population of a country like the United States to fall off. But this is not confirmed so far by any figures of a completely trustworthy kind, while the falling off in the rate of growth to be here accounted for is too great and sudden to be explained in such a manner.

The blunder is thus left quite unexplained, and the people of the United States, we may hope, will not fail to see to it. It concerns wider than merely national interests that the blunder should be seen to. For purposes of comparison, every census in the world is thrown out. Looking at the causes of the errors in the 1870 census, viz. an attempt to understate the numbers of the people in Democratic States, and at the special complaints of under-statement which have now come from New York and other Democratic centres, we have altogether too much reason to fear that the cause of the blundering is political. But, whatever the cause may be, it should be stringently looked into.

\section{SPIDERS' WEBS}

American Spiders and their Spinning Work : a N'atural History of the Orb-weaving Spiders of the United States, with Special Regard to their Industry and Habits. By Henry C. McCook, D.D. Vol. II. pp. I-479, with 5 Coloured Plates and $40 \mathrm{I}$ Woodcut Figures. (Philadelphia: Allen Lane and Scott, 1890.)

$\mathrm{T}$ a notice of vol. i. of the above work (NATURE, vol. xlii. p. 244), its object and scope were explained. Vol. ii., now before us, fully justifies what was there stated as to the thoroughness with which the available materials on the subject have been brought together from all sources, and for the first time presented to the world as a whole. A similar popular treatment also of this interesting and most important part of the subject is again here observable. Vol. i. was occupied with the snares and web-spinning of orb-weaving and some other spiders, principally in relation to the getting of their livelihood. Vol. ii. treats of these spiders in respect to the propagation of their kind, and web-spinning as subservient to this. Vol. i., in fact, presents us with spiders safely NO. I IOO, VOL. 43] arrived at maturity, and forming their snares and webs with all the diversity and perfection peculiar to each species; while vol. ii. takes them up at that point, and shows them to us in all the different peculiarities pertaining to the performance of the ultimate object of their existence. Naturally, therefore, the volume before us begins (part i., chapter i.), with an account of the sexes in their relation to each other preparatory to actual pairing. This latter and the points arising out of it form the staple of chapters ii. and iii., which complete part i. A certain air of sentimental allusion, which appears to pervade the author's method of presenting this part of his subject, is perhaps merely a matter of taste, and so beyond the province of scientific criticism. It may be, however, that this, while it certainly adds nothing to scientific accuracy or progress, does add to the popularity of the subject, which is evidently throughout the wor's one of its author's great objects. On the small size of many male spiders compared with their bulky females, Dr. McCook does not appear to accept the views of a former writer upon it, in which it should be observed that the primitive equality in the size of the sexes is by no means implied; the general rule being that the male is the smaller of the two. But if it be granted that the female had a propensity for attacking and devouring the male, those males which happened to be the smallest and most active would be the most likely to escape, and perform the functions of the sex; natural selection would then come in, and operate gradually in the direction of lessening the size of the males. That there are numerous spiders, and groups of spiders, in which the sexes are nearly equal in size, or live in amity together, or in which the males are furnished with some protective armature against the ferocity of the female, proves nothing against the theory of the action of natural selection in lessening the size of the male in such cases as those where a devouring propensity existed and was otherwise unprovided against; for in groups where any approach to equality in size existed and became protective, or where some other protection became developed, there would be no need, in fact no case, for natural selection in the direction of diminished size, there being no advantage to be gained under it. The drift, however, of the author s. reasoning on this subject (p. 7) is not very apparent.

Part ii. treats of the "Maternal Industry and Instincts of Spiders"; embracing the formation of cocoons for the reception of their eggs, and the bringing into existence of the young, which naturally leads (part iii.) to the consideration of the life of the young while still engaged in the struggle for existence necessary for the survival of the fittest. The dispersion of spiders on the approach of maturity leads to an account of their method of locomotion on gossamer lines and flakes, completing part iii.

Part iv. enters into the subject of the senses of spiders, and their relation to habit. The structure of the eyes, and their functions are gone into in considerable detail. The remarkable position of these organs in the males of some species-such as Walckenaera acuminata, Blackw., in which they are seated near or at the top of a very long slender kind of footstalk -is mentioned; and it is supposed (p. 298) that this might give the male spider an advantage when in search of the female; but, apart from this explanation not being warranted by any known facts as to the 